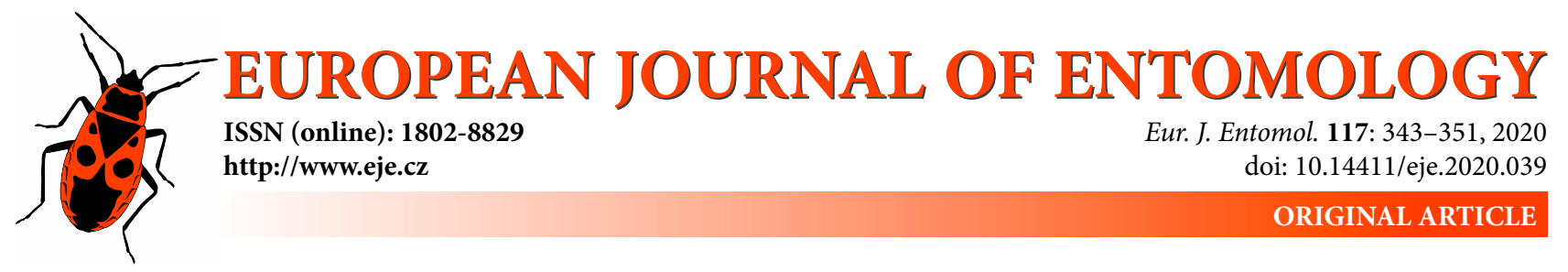

\title{
Revision of the assassin bug genus Neopirates (Heteroptera: Reduviidae: Peiratinae), with descriptions of two new species from Namibia
}

\author{
YINGQI LIU1 ${ }^{1}$, Zhuo CHEN ${ }^{1}$, Michael D. WEBB ${ }^{2}$ and WANZHI CAI ${ }^{1, *}$ \\ ${ }^{1}$ Department of Entomology and MOA Key Lab of Pest Monitoring and Green Management, China Agricultural University, \\ Yuanmingyuan West Road, Beijing 100193, China; e-mails: yingqiliu0720@163.com; insectchen625@126.com; \\ caiwz@cau.edu.cn \\ ${ }^{2}$ Department of Life Sciences (Insects), The Natural History Museum, Cromwell Road, London SW7 5BD, U.K.; \\ e-mail:m.webb@nhm.ac.uk
}

Key words. Reduviidae, Peiratinae, Neopirates, Sphodrembas, taxonomy, new species, new synonymy, Afrotropical Region, Namibia

\begin{abstract}
The African assassin bug genus Neopirates Miller, 1952, is revised. The type species, N. nyassae Miller, 1952, is redescribed and illustrated; two new species from Namibia, N. bicolor Liu \& Cai sp. n. and N. xanthothorax Liu \& Cai sp. n. are described and a key is provided to separate the three species of this genus. Sphodrembas fumipennis Swanson, 2019, the type species of Sphodrembas Swanson, 2019, is placed as a junior synonym of N. nyassae, resulting in Sphodrembas becoming a junior synonym of Neopirates. Morphological differences between Neopirates and similar genera and the distribution of Neopirates are briefly discussed.
\end{abstract}

ZooBank Article Registration: http://zoobank.org/urn:Isid:zoobank.org:pub:10E250F1-27F7-4F11-95AD-BCACE78AE33E

\section{INTRODUCTION}

As one of the largest assassin bug subfamilies, Peiratinae (Reduviidae) is a diverse taxon comprising 34 genera and over 300 species distributed worldwide (MaldonadoCapriles, 1990; Chłond, 2007; Zhang \& Weirauch, 2011; Melo, 2012; Weirauch et al., 2014; Swanson, 2019). The following combination of characters makes Peiratinae a unique group within Reduviidae: anterior pronotal lobe longer than posterior lobe, elongate forecoxa, prominent fossula spongiosa on the fore and mid tibiae, and asymmetrical male genitalia (Weirauch et al., 2014). Up to now, there have been 18 peiratine genera recorded in the Afrotropical Region but only a few of them have been well reviewed (Coscarón, 1995, 1997, 1999, 2002; Coscarón \& Morrone, 1995; Zhang \& Weirauch, 2011; Chłond, 2018). Moreover, many Afrotropical peiratine genera are monotypic, not only reflecting the morphological diversity of this group but also indicating that the true species diversity will be revealed through more detailed studies.

Neopirates was established by Miller (1952) based on a single species, Neopirates nyassae Miller, 1952, from
Nyasaland (now Malawi); after nearly 70 years, Neopirates remains monotypic. Recently, Swanson (2019) proposed another monotypic peiratine genus Sphodrembas (type species: Sphodrembas fumipennis Swanson, 2019), based on specimens from Tanzania and Kenya, with a very detailed description. However, after examining the holotype of $N$. nyassae and comparing it with the figures and original description of $S$. fumipennis, we found that they should be the same species. We therefore propose $S$. fumipennis as a junior synonym of $N$. nyassae, syn. n., and thus Sphodrembas as a junior synonym of Neopirates, syn. n. Besides, during our examination of museum specimens, two new Neopirates species from Namibia were identified. In the present study, the genus Neopirates is reviewed and a modified generic diagnosis given. A redescription of the type species and descriptions of the two new species are provided together with a key for their separation. Morphological differences between Neopirates and its similar genera, together with distribution and habitat of Neopirates are also briefly discussed.

\footnotetext{
* Corresponding author; e-mail: caiwz@cau.edu.cn
} 


\section{MATERIAL AND METHODS}

This study is based on specimens deposited in the Natural History Museum, London, UK (NHMUK) and the Natural History Museum of Los Angeles County, California, USA (LACM). Label data are copied verbatim in quotation marks (" ") with different labels separated by a double slash (//). Male genitalia were soaked in hot $20 \%$ lactic acid solution for approximately ten minutes to remove soft tissue, rinsed in distilled water and dissected under a dissecting microscope. Dissected genitalia were placed in vials with glycerin and pinned under the corresponding specimens after examination. Images were taken using a Canon 7D Mark II digital camera with Canon EF $100 \mathrm{~mm}$ micro lens or $65 \mathrm{~mm}$ micro lens and an Olympus E-M1 II digital camera with Olympus M. ZUIKO digital ED $60 \mathrm{~mm}$ micro lens. Helicon Focus version 5.3 was used for image stacking. Measurements were obtained using a calibrated micrometer. Body length represents the distance between the apex of the head and the tip of the abdomen in resting condition. The distribution map was built using the online version of SimpleMapper (Shorthouse, 2010). The distribution data are based on our examination of museum specimens, supplemented by data from Miller (1952) and Swanson (2019). Morphological terminology mainly follows Lent \& Wygodzinsky (1979), Cai \& Taylor (2006) and Swanson (2019).

\section{TAXONOMY}

\section{Genus Neopirates Miller, 1952}

(Figs 1-61)

Neopirates Miller, 1952: 551-552; Maldonado-Capriles, 1990: 362. Type species: Neopirates nyassae Miller, 1952, by monotypy.

Sphodrembas Swanson, 2019: 210-211. Type species: Sphodrembas fumipennis Swanson, 2019, by original designation. New synonymy.

Diagnosis. Male macropterous (Figs 1-3, 21-23, 4143), female unknown; head moderately elongate with postocular part somewhat abruptly narrowed (Figs 4, 24, 44); transverse width of eye in dorsal view subequal to width of interocular space (Figs 4, 24, 44); anterior lobe of pronotum subquadrate; pronotal transverse sulcus obsolete (Figs 24,44 ) or slight (Fig. 4); metapleural sulcus curved and unicarinate (Figs 5, 25, 45); fore tibia with fossula spongiosa occupying about $1 / 3$ (Figs 27,47 ) or 1/4 (Fig. 7) of tibial length, mid tibia with fossula spongiosa occupying only apex of ventral surface (Figs 8, 28, 48); hind coxae separated from each other by width of one coxa (Figs 6, 26, 46); hemelytron and hind wing both extending beyond tip of abdomen (Figs 10, 30, 50); male genitalia with median pygophore process nearly straight, oblique to right side in caudal view, ventral surface of median pygophore process with a longitudinal ridge (Figs 13, 14, 33, 34, 53, 54); base of left lateral phallothecal sclerite with a slender, strongly sclerotized sclerite, extending to venter of phallosoma, venter of phallosoma with another slender sclerite, shorter than lateral one and nearly connected to it (Figs 18, 19, 38, 39, 58, 59).

Redescription. Macropterous male (Figs 1-3, 21-23, 41-43), female unknown.

Coloration. Yellow and brown in large part, sometimes with intraspecific variation in color of head, pleura, sterna
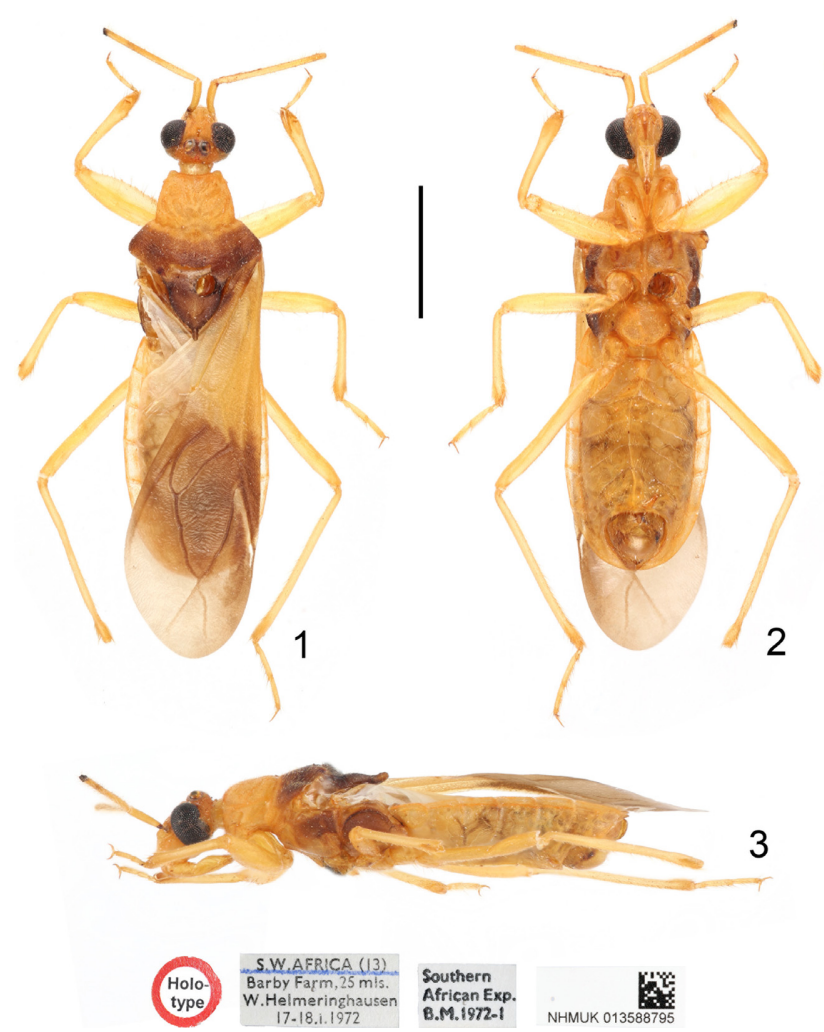

Figs 1-3. Neopirates bicolor sp. n., holotype male, habitus. 1 dorsal view; 2 - ventral view; 3 - lateral view. Scale bar $=3.00 \mathrm{~mm}$.

and abdomen (Figs 1-3, 21-23, 41-43). Head with irregular blackish mark around ocelli (Figs 4, 24, 44); legs entirely yellow (Figs 1-3, 21-23, 41-43).

Structure. Small to medium sized. Body surface and costal area of corium densely covered with yellow, procumbent, short pubescence; first and second antennal segments with yellowish brown, suberect, short setae; ventral surface of femora, ventral and lateral surfaces (especially apex) of tibiae and ventral surface of tarsi covered with yellow to brown, suberect or erect, thick setae of varying lengths (Figs 1-3, 21-23, 41-43).

Head moderately elongate with anteocular part longer than postocular, postocular part somewhat ellipsoidal; interocular space with a median, short, deep sulcus connecting to frontoclypeal sulcus (Figs 4, 24, 44). Eye large, width of eye subequal to width of interocular space in dorsal view (Figs 4, 24, 44), reniform in lateral view, reaching dorsal margin and nearly reaching ventral margin of head (Figs 5, 25, 45). Ocelli located on small tubercles (Figs 5, $25,45)$, width of interocellar space one to two times width of ocellus (Figs 4, 24, 44). First antennal segment thickest and shortest, second segment slender and longest, third and fourth segments gracile. First and second visible rostral segments thick, second segment longest and slightly swollen, third segment tapered (Figs 5, 6, 25, 26, 45, 46). Neck with 1+1 weakly developed tubercles (Figs 4, 24, 44).

Pronotum with collar process developed; anterior lobe of pronotum longer and narrower than posterior lobe; anterior lobe of pronotum subquadrate with a median, longitudinal, shallow sulcus on posterior portion, sculpture not clear; 

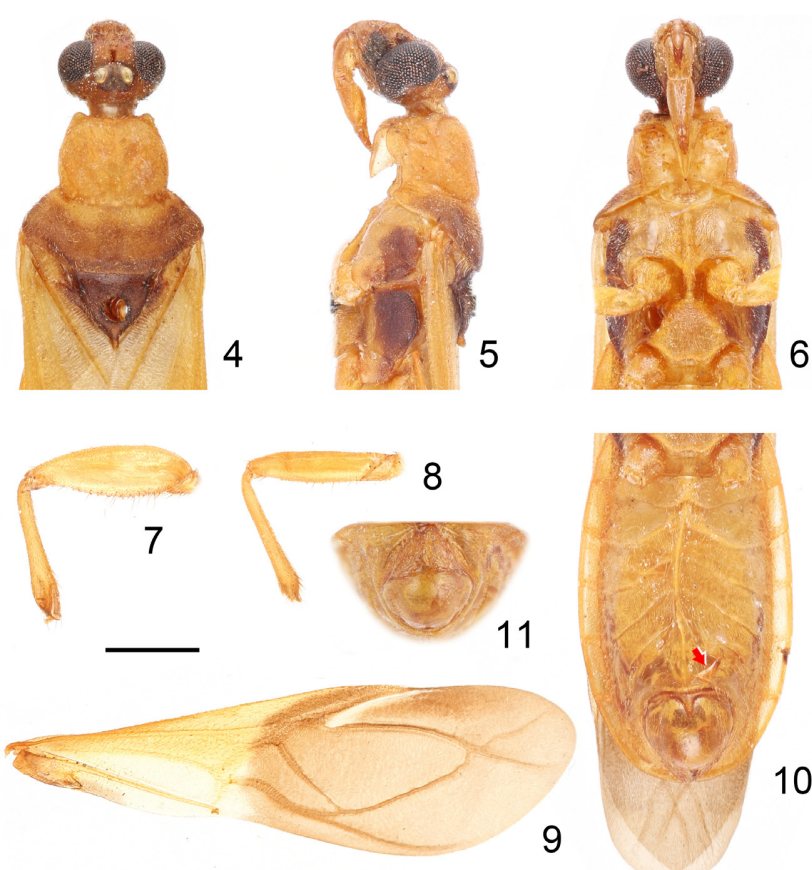

6
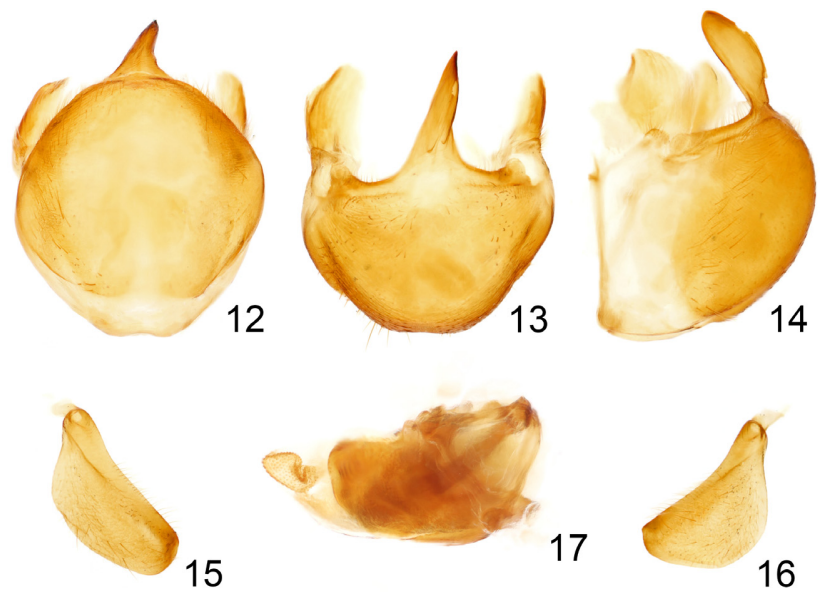

17
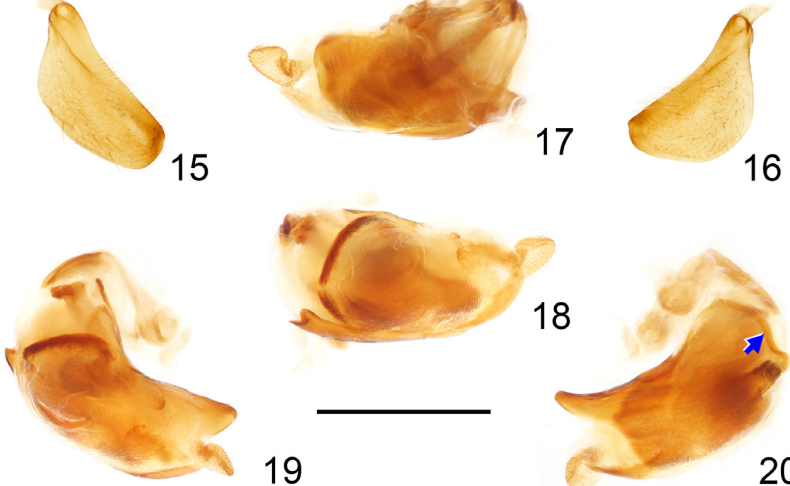

19

Figs 4-11. Neopirates bicolor sp. n., paratype male. 4-6 - anterior part of body with antennae and legs removed; 7 - left fore leg without tarsus; 8 - right mid leg without tarsus; 9 - right hemelytron; 10 , 11 -abdomen. 4, 9 -dorsal view; 5 - lateral view; 6-8, 10 -ventral view; 11 - caudal view. Arrow indicates the extragenital process. Scale bar $=1.50 \mathrm{~mm}$

pronotal transverse sulcus obsolete or slight ( $N$. bicolor sp. n.); surface of posterior lobe of pronotum coarse, lateral pronotal angle round, posterior margin of pronotum nearly straight in middle but slightly concave bilaterally (Figs 4, 24, 44). Scutellum subtriangular (Figs 4, 24, 44), Y-shaped ridges thick with apex of scutellum rounded (Figs 24, 44) or Y-shaped ridges slender with apex of scutellum prolonged as a small process (Fig. 4). Stridulitrum fairly long to long with total-striate type of sculpture (Figs 6, 26, 46). Surfaces of pleura and sterna finely wrinkled (Figs 5, 6, 25, $26,45,46$ ); metapleural sulcus represented only by single curved carina (Figs 5, 25, 45); mesosternum with a median longitudinal ridge (Figs 6, 26, 46). Fore femur slightly thickened (Figs 7, 27, 47), thicker than mid and hind femora; fore tibia clavate, gradually thickened to apex, apex of inner surface with a tibial comb, fossula spongiosa occupying about $1 / 3$ or $1 / 4$ of tibial length (Figs $7,27,47$ ); mid tibia with fossula spongiosa occupying only apex of ventral surface (Figs 8, 28, 48); hind coxae separated from each other by width of one coxa (Figs 6, 26, 46). Hemelytron distinctly extending beyond tip of abdomen, hind wing also extending beyond tip of abdomen (Figs 10, 30, 50).

Abdomen oval; connexivum slightly dilated laterally; venter of abdomen slightly carinate in middle (Figs 30, 50 ) or with a median ridge running from anterior of second abdominal sternite to posterior of seventh abdominal sternite and slightly curved to right side of body (Fig. 10); left side of seventh abdominal sternite sometimes with an extragenital process (Figs 10, 50).
Figs 12-20. Male genitalia of Neopirates bicolor sp. n., paratype. 12-14 - pygophore; 15 - left paramere; 16 - right paramere; 17-20 - phallus. 12, 18 - ventral view; 13 - caudal view; 14, 19, 20 - lateral view; 15,16 - outer ventrolateral view; 17 -dorsal view. Blue arrow indicates the basal margin of the right lateral phallothecal sclerite. Scale bar $=1.00 \mathrm{~mm}$.

Male genitalia asymmetric (Figs 11-20, 31-40, 51-60). Pygophore oval in ventral view (Figs 12, 32, 52); median pygophore process nearly straight, oblique to right side in caudal view, ventral surface with a longitudinal ridge (Figs 13, 33, 53). Left paramere (Figs 15, 35, 55) slightly longer and slenderer than right paramere (Figs 16, 36, 56). Phallus with phallobase weakly sclerotized, length of basal plate bridge subequal to basal plate (Figs 17, 37, 57); pedicel slightly curved and shorter than basal plate (Figs 19, 39, 59). Dorsal phallothecal sclerite strongly sclerotized, broad and bent inward with apex bluntly rounded (Figs 17, 37, 57); Base of left lateral phallothecal sclerite with a slender, strongly sclerotized sclerite, extending to venter of phallosoma, venter of phallosoma with another slender sclerite, shorter than lateral one and nearly connecting to it (Figs $18,19,38,39,58,59)$.

Remarks. See discussion for details on generic synonymy.

\section{Key to species of Neopirates Miller}

1 Scutellum with Y-shaped ridges slender, apex of scutellum prolonged as a small process (Fig. 4); hemelytron with basal half yellow and apical half brown (Fig. 9); venter of male abdomen with a curved, median ridge running from anterior of second abdominal sternite to posterior of seventh abdominal sternite (Fig. 10) ........................... N. bicolor Liu \& Cai sp. n.

- Scutellum with Y-shaped ridges thick, apex of scutellum rounded (Figs 24, 44); hemelytron brown (Figs 29, 49); venter of male abdomen slightly carinate in middle (Figs 30, 50)
Distribution. Afrotropical Region (Fig. 61). 

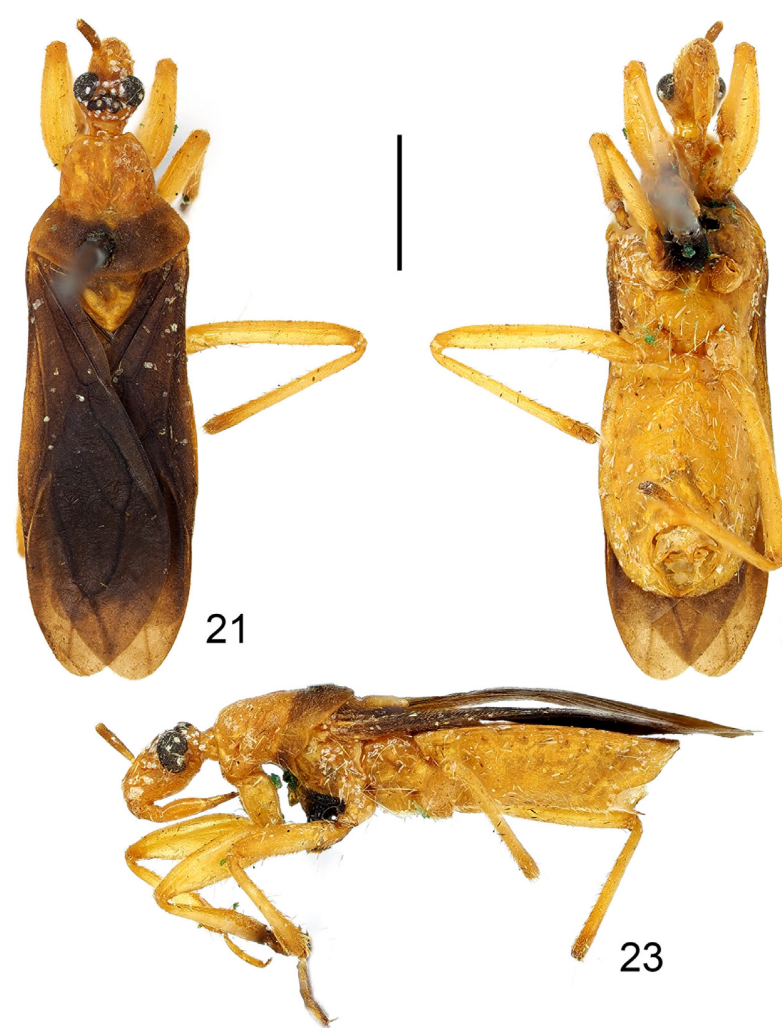

22

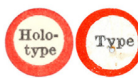

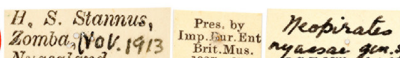

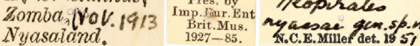

Figs 21-23. Neopirates nyassae, holotype male, habitus. $21-$ dorsal view; 22 - ventral view; 23 - lateral view. Scale bar $=3.00 \mathrm{~mm}$.

2 Body length over $10 \mathrm{~mm}$; pronotum with anterior lobe yellow and posterior lobe brown (Fig. 24); seventh abdominal sternite without extragenital process (Fig. 30) .

N. nyassae Miller, 1952

- Body length less than $10 \mathrm{~mm}$; pronotum entirely yellow (Fig. 44); left side of seventh abdominal sternite with a small fusiform extragenital process (Fig. 50).

N. xanthothorax Liu \& Cai sp. n.

\section{Neopirates bicolor Liu \& Cai sp. $\mathrm{n}$.}

(Figs 1-20, 61)

ZooBank taxon LSID:

6D9C96E4-D545-4482-BCA7-659159B3DAEF

Diagnosis. Body length 9.87-9.93 mm; anterior lobe of pronotum yellow, posterior lobe brown with basal margin yellow; hemelytron bicolored, basal half yellow, apical half brown with lateral margin darker; pronotal transverse sulcus slight; scutellum with Y-shaped ridges slender, apex of scutellum prolonged as a small process; fore tibia with fossula spongiosa occupying about $1 / 4$ of tibial length; venter of abdomen with a median ridge slightly curved to right side of body and a triangular extragenital process; left paramere paddle-shaped, right paramere nearly trapeziform; apex of median pygophore process rounded in lateral view; basal margin of right lateral phallothecal sclerite smooth.

Description. Male macropterous (Figs 1-3), female unknown. Coloration. Yellow. First antennal segment yellow, second segment yellow with apical portion brownish,
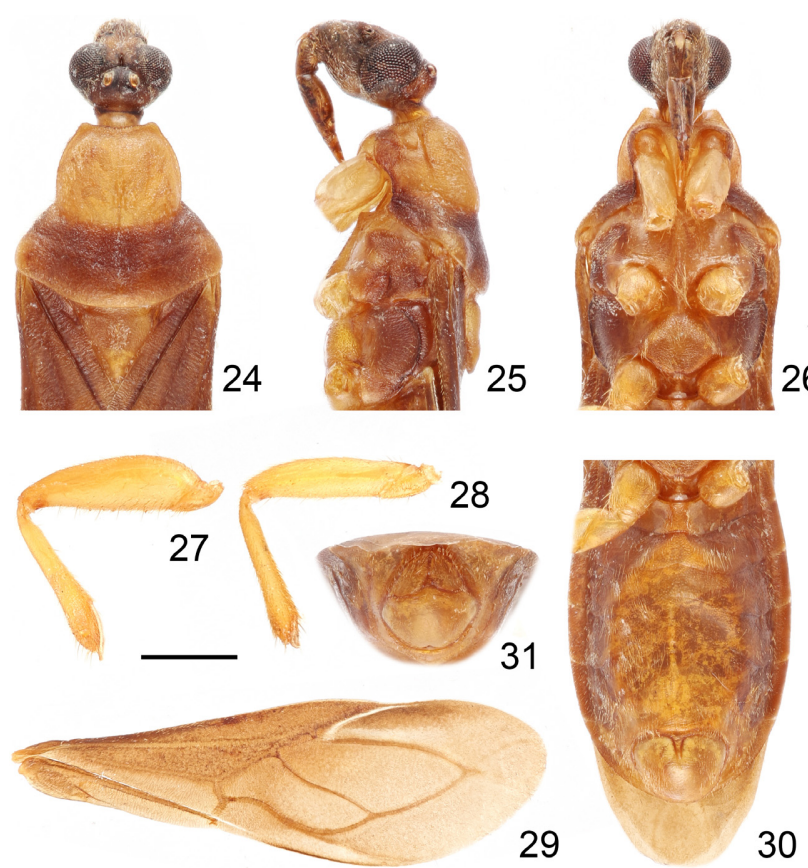

Figs 24-31. Neopirates nyassae, male (Lesotho). 24-26 - anterior part of body with antennae and legs removed; 27 - left fore leg without tarsus; 28 - right mid leg without tarsus; 29 - right hemelytron; 30, 31 - abdomen. 24, 29 - dorsal view; 25 - lateral view; 26-28, 30 - ventral view; 31 - caudal view. Scale bar $=1.50 \mathrm{~mm}$.

third segment brown with apex yellow, fourth segment unknown; head dark yellow to yellowish brown with irregular blackish mark around ocelli (Fig. 4) and sometimes with blackish spot in front of eye on lateral surface of head (Fig. 5); anterior lobe of pronotum yellow, posterior lobe brown with basal margin yellow (Fig. 4); scutellum brown (Fig. 4); pleura brown with margin diffused yellow (Fig. 5 ); basal half of hemelytron yellow, apical half of hemelytron brown with lateral margin darker, membrane with a whitish stripe along inner side of R (Fig. 9); abdomen yellow, sometimes with some diffuse brown markings laterally (Fig. 10).

Structure: Small sized. Head length 1.13-1.21 times as long as its width; width of interocellar space subequal to width of ocellus (Fig. 4); second antennal segment about three times as long as first segment. Pronotum with apex of collar process rounded; anterior lobe of pronotum 1.27-1.30 times longer than posterior lobe; posterior lobe of pronotum about 1.65-1.71 times wider than anterior lobe; pronotal transverse sulcus slight (Fig. 4). Scutellum with Y-shaped ridges slender, apex of scutellum prolonged as a small process (Fig. 4). Stridulitrum fairly long with total-striate type of sculpture (Fig. 6). Fore tibia with fossula spongiosa occupying about $1 / 4$ of tibial length (Fig. 7). Venter of abdomen with a median ridge running from anterior of second abdominal sternite to posterior of seventh abdominal sternite, slightly curved to right side of body and with a triangular extragenital process on left side of seventh abdominal sternite (Fig. 10).

Male genitalia: Median pygophore process relatively broad with apex rounded in lateral view (Fig. 14); left paramere paddle-shaped (Fig. 15), right paramere nearly tra- 

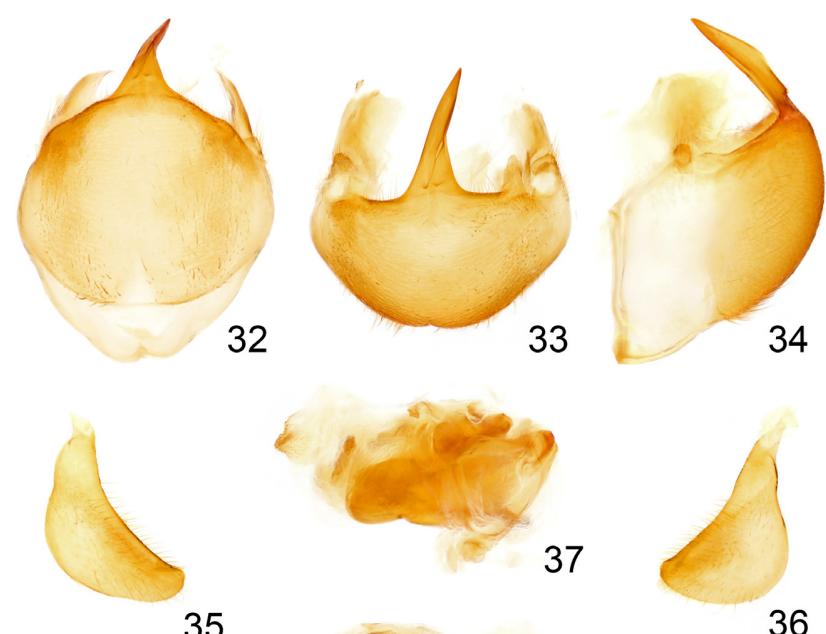

35
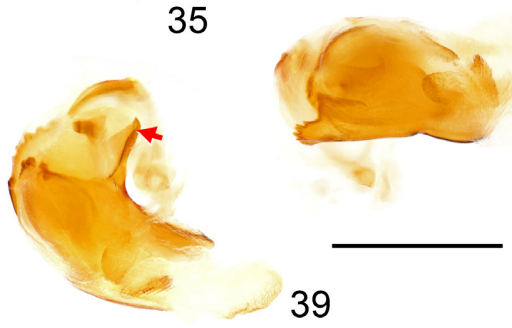

36
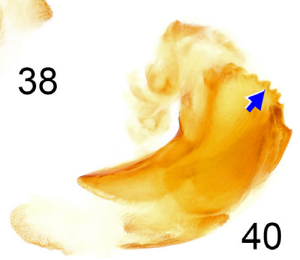

Figs 32-40. Male genitalia of Neopirates nyassae. 32-34 - pygophore; 35 - left paramere; 36 - right paramere; $37-40$ - phallus. 32, 38 - ventral view; 33 - caudal view; 34, 39, 40 - lateral view; 35,36 - outer ventrolateral view; 37 - dorsal view. Red arrow indicates the upturned basal portion of the dorsal phallothecal sclerite and blue arrow indicates the basal margin of the right lateral phallothecal sclerite. Scale bar $=1.00 \mathrm{~mm}$.

peziform (Fig. 16); left lateral phallothecal sclerite nearly membranous, with basal slender sclerite extremely sclerotized (Fig. 19); right lateral phallothecal sclerite moderately sclerotized, basal margin smooth with lower $1 / 3$ concave inward (Fig. 20); apex of endosoma with a small sacciform process, of which surface densely covered with tiny tubercles (Figs 17-20).

Measurements [in mm, $\widehat{\delta}(\mathrm{n}=2)$ ]. Body length 9.87-9.93; maximum width of abdomen 3.09-3.19; head length 1.80-1.92; length of anteocular part $0.70-0.73$; length of postocular part $0.38-0.40$; head width 1.59-1.59; eye width in dorsal view $0.52-0.50$; width of interocular space $0.54-0.58$; width of interocellar space $0.20-0.21$; lengths of rostral segments I: II : III = $0.56-0.65: 0.76-0.76: 0.48-0.50$; lengths of antennal segments I : II : III : IV $=0.80-?: 2.39-?:$ ?-? : ?-?; length of anterior pronotal lobe 1.35-1.40; length of posterior pronotal lobe 1.04-1.10; width of anterior pronotal lobe 1.64-1.64; width of posterior pronotal lobe 2.80-2.71; scutellum length 1.36-1.17; maximum width of scutellum 1.44-1.60; hemelytron length 8.90-8.51.

Type material. Namibia: Holotype $\sigma^{\lambda}$ : red-margined "Holotype" disc // "S. W. AFRICA (13) Barby Farm, 25 mls. W. Helmeringhausen 17-18. I. 1972" // "Southern African Exp. B.M.1972-1" // "NHMUK 013588795" (NHMUK); Paratype 10: yellow-margined "Paratype" disc // "S.W. AFRICA: Sissekab. 14.XI.1933. K. Jordan.” // "Brit. Mus. 1934-110.” // "NHMUK 013588796" (NHMUK).

Other material examined. Namibia: 1? (without abdomen): "S.W. AFRICA: Otjikata Lake [= Otjikoto Lake]. 16.xi.1933. K. Jordan." // "Brit. Mus. 1934-110." // "NHMUK 013588797" (NHMUK).

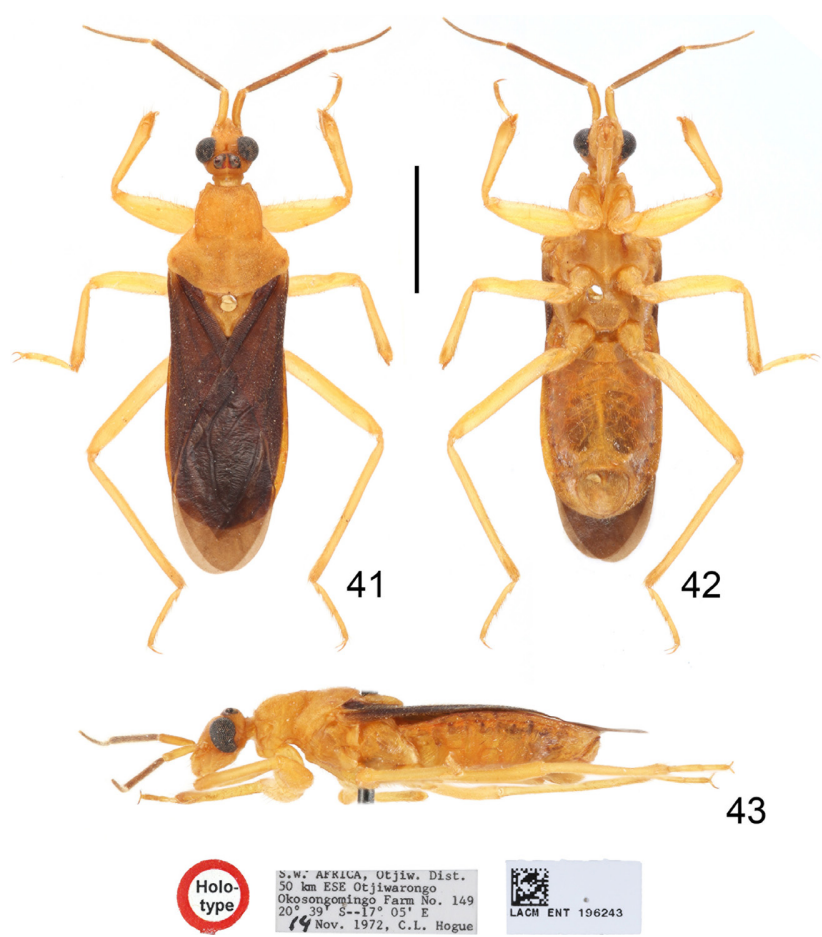

Figs 41-43. Neopirates xanthothorax sp. n., holotype male, habitus: 41 - dorsal view; 42 - ventral view; 43 - lateral view. Scale bar $=3.00 \mathrm{~mm}$.

Type locality. Namibia, Karas Region, Berseba, Barby Farm, $25^{\circ} 51^{\prime} \mathrm{S}, 16^{\circ} 33^{\prime} \mathrm{E}$.

Etymology. The specific epithet is derived from Latin bicolor (meaning "of two colors"), referring to the conspicuously bicolored hemelytron of this new species.

Distribution. Namibia.

Remarks. Of the three specimens of this new species found in NHMUK one is missing the abdomen, so we exclude it from the type series. The intraspecific color variation of this new species is mainly in the head and abdomen: the head of the holotype is dark yellow (Figs 1-3) but the head of the paratype is yellowish brown with a blackish spot in front of the eye on the lateral surface (Figs 4-6) and the abdomen of the paratype (Fig. 10) with more diffuse brownish markings laterally than that of the holotype (Fig. 2).

This new species can be easily distinguished from its congeners due to its bicolored hemelytron, the pronotal transverse sulcus slight and the apex of the scutellum prolonged as a small process instead of rounded. Besides these features, the most special character is the distinct triangular extragenital process on the left side of the seventh abdominal sternite. This kind of extragenital process was first studied by Ghauri (1964) who found that they always occur on the left-hand side of the body and their function could be related to mating behavior. Such extragenital process cannot be included in the generic diagnosis because this structure may only be present in some species of the same genus, such as species in Peirates Serville, 1831, and Phalantus Stål, 1863. In Neopirates, the extragenital process is only present in this new species and N. xanthothorax $\mathrm{sp} . \mathrm{n}$. and their shapes are totally different (smaller and 

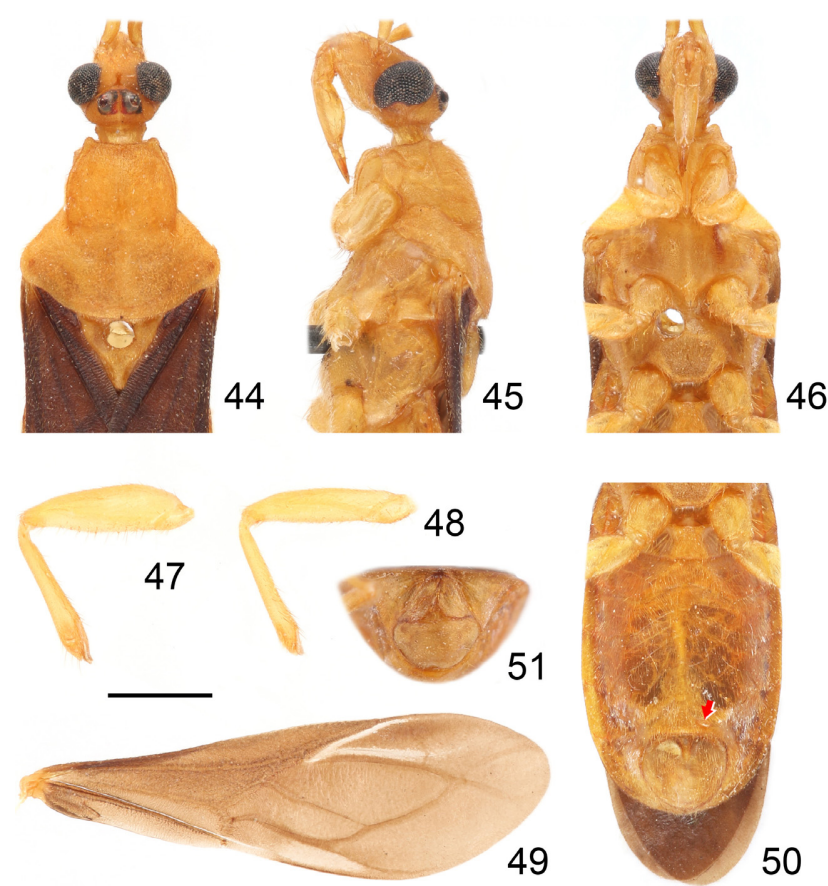

Figs 44-51. Neopirates xanthothorax sp. n., holotype male. 44-46 - anterior part of body with antennae and legs removed; 47 - left fore leg without tarsus; 48 - right mid leg without tarsus; 49 - right hemelytron; 50, 51 - abdomen. 44, 48 - dorsal view; 45 - lateral view; 46-48, 50 - ventral view; 51 - caudal view. Arrow indicates the extragenital process. Scale bar $=1.50 \mathrm{~mm}$.

fusiform in $N$. xanthothorax sp. n.). The male genitalia of this new species differ from those of other Neopirates species in the apex of the median pygophore process rounded instead of sharp in the lateral view and the basal margin of the right lateral phallothecal sclerite smooth instead of serrate.

\section{Neopirates nyassae Miller, 1952}

(Figs 21-40, 61)

Neopirates nyassae Miller 1952: 552, fig. 10; MaldonadoCapriles, 1990: 362 (catalogue).

Sphodrembas fumipennis Swanson, 2019: 211-214, figs 11-14. New synonymy.

Diagnosis. Body length 10.11-14.5 mm; anterior lobe of pronotum dark yellow, posterior lobe brown; hemelytron brown; anterior lobe of pronotum about 1.30-1.50 times longer than posterior lobe, pronotal transverse sulcus obsolete; scutellum with Y-shaped ridges thick, apex of scutellum rounded; fore tibia with fossula spongiosa occupying slightly longer than $1 / 3$ of tibial length; venter of abdomen only slightly carinate in middle, without extragenital process; parameres subtriangular; apex of median pygophore process sharp in lateral view; basal portion of dorsal phallothecal sclerite distinctly upturned; basal margin of right lateral phallothecal sclerite serrate.

Redescription. Male macropterous (Figs 21-23), female unknown. Coloration. Yellow, color of head, pleura, sterna and abdomen varies from yellow to brown among conspecific individuals. Antenna dark yellow; head yellow
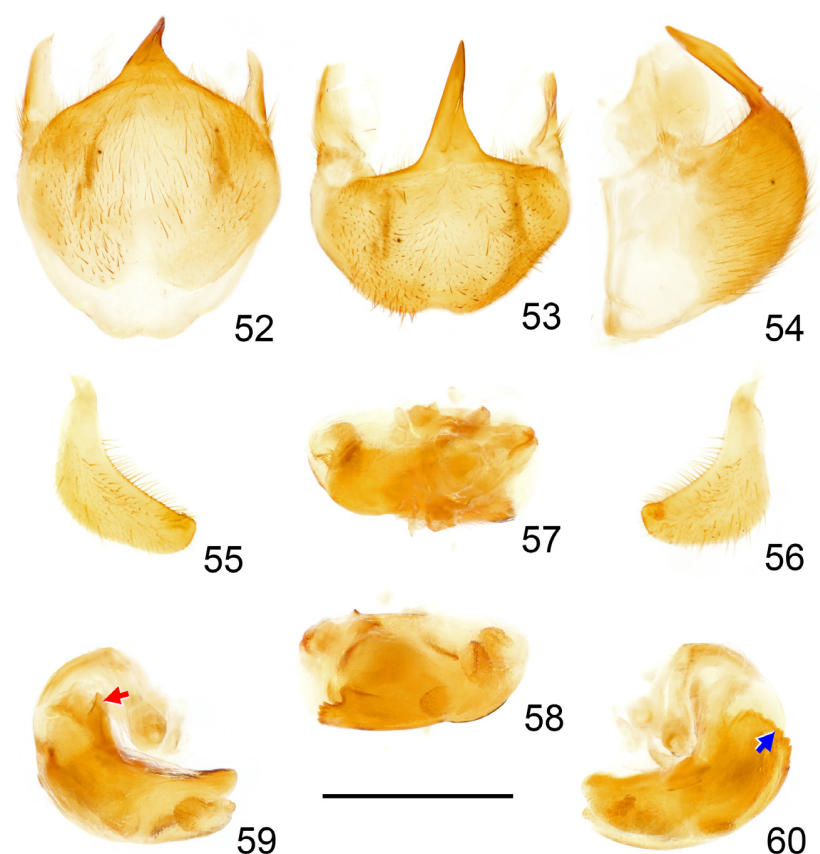

59

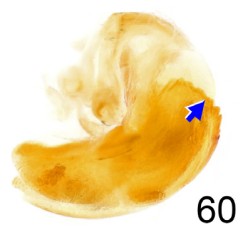

Figs 52-60. Male genitalia of Neopirates xanthothorax sp. n., holotype. 52-54 - pygophore; 55 - left paramere; 56 - right paramere; 57-60 - phallus. 52, 58 - ventral view; 53 - caudal view; 54, 59, 60 - lateral view; 55, 56 - outer ventrolateral view; 57 - dorsal view. Red arrow indicates the upturned basal portion of the dorsal phallothecal sclerite and blue arrow indicates the basal margin of the right lateral phallothecal sclerite. Scale bar $=1.00 \mathrm{~mm}$.

(Fig. 21) to brown (Fig. 24) with irregular blackish mark around ocelli (Figs 21, 24); anterior lobe of pronotum dark yellow, posterior lobe brown (Fig. 24); pleura, sterna and abdomen yellow (Figs 22, 23) to yellowish brown (Figs 25, 26,30 ), sometimes with diffuse brown markings (Figs 25, $26,30)$; hemelytron brown with a whitish thin stripe along R on membrane (Fig. 29).

Structure. Medium sized. Head length 1.30 times as long as width; width of interocellar space slightly longer than width of ocellus (Fig. 24); second antennal segment about twice as long as first segment. Pronotum with apex of collar process rounded; anterior lobe of pronotum about 1.30-1.50 times longer than posterior lobe; posterior lobe of pronotum 1.65 times wider than anterior lobe; pronotal transverse sulcus obsolete (Fig. 24). Scutellum with Y-shaped ridges thick, apex of scutellum rounded (Fig. 24); Stridulitrum long with total-striate type of sculpture (Fig. 26). Fore tibia with fossula spongiosa occupying slightly longer than $1 / 3$ of tibial length (Fig. 27). Venter of abdomen only slightly carinate in middle, without extragenital process (Fig. 30).

Male genitalia: Median pygophore process slender, apex sharp, base with a small spine in lateral view (Fig. 34); parameres subtriangular (Figs 35, 36); basal portion of dorsal phallothecal sclerite distinctly upturned (Fig. 39); left lateral phallothecal sclerite moderately sclerotized (Fig. 39); right lateral phallothecal sclerite moderately sclerotized, basal margin serrate (Fig. 40); endosoma somewhat capsule-shaped, apical surface densely covered with tiny tubercles (Figs 39, 40). 
Measurements [in mm, $\widehat{\partial}(\mathrm{n}=3)$ ]. Body length 10.11-12.19; maximum width of abdomen 3.21-3.55; head length 1.92-1.96; length of anteocular part $0.79-0.90$; length of postocular part $0.40-0.34$; head width $1.49-1.50$; eye width in dorsal view $0.50-0.50$; width of interocular space $0.49-0.50$; width of interocellar space $0.21-0.28$; lengths of rostral segments I: II : III = $0.51-0.79: 1.10-1.17: 0.43-0.81$; lengths of antennal segments $\mathrm{I}: \mathrm{II}: \mathrm{III}: \mathrm{IV}=1.00-1.19:$ ?-? : ?-? : ?-?; length of anterior pronotal lobe 1.48-1.85; length of posterior pronotal lobe 1.12-1.24; width of anterior pronotal lobe 1.81-2.06; width of posterior pronotal lobe 3.00-3.40; scutellum length 1.10-1.12; maximum width of scutellum 1.48-1.67; hemelytron length 7.78-9.50.

Type material. Malawi: Holotype $\delta$ : red-margined "Holotype" disc // red-margined "Type" disc // "H. S. Stannus, Zomba, Nov. 1913 Nyasaland.” // "Pres. by Imp. Bur. Ent. Brit. Mus. 1927-85." // "Neopirates nyassae gen. sp. n. N.C.E. Miller det. 1951" // "NHMUK 013586510" (NHMUK).

Other material examined. Kenya: $1 \delta^{\lambda}$ : "Managya Funde B.E. Africa. C.S. Betton. 98-12. Taru Desert" // "NHMUK 013588799” (NHMUK); Lesotho: 1ठ: “A. Turner Sekoke. July. 1932" // "NHMUK 013588798” (NHMUK).

Distribution. Malawi, Tanzania, Kenya, Lesotho (new record).

Remarks. The body color varies from yellow to brown among individuals in this species. The color of the head, the thorax (except the pronotum) and the abdomen of the holotype (Figs 21-23) is yellow in large part while it's different shades of brown or with some brownish markings in the other examined specimens. Other structural characters and the colors of the pronotum (the anterior lobe dark yellow while the posterior lobe brown), the legs (entirely yellow) as well as the irregular blackish mark around the ocelli are stable among all the examined specimens. We therefore conclude that the color variation mentioned above is an intraspecific difference.

The new junior synonym of this species, Sphodrembas fumipennis, was described based on the holotype male from Tanzania and four paratypes from Tanzania and Kenya (deposited in the American Museum of Natural History and the University of Michigan Museum of Zoology). Based on the original description, the color of these specimens is also variable, and the hemelytra are surrounding fuscous in Kenyan specimens but concolorously fuscous in Tanzanian specimens. See discussion for details on synonymy.

\section{Neopirates xanthothorax Liu \& Cai sp. $\mathbf{n}$.}

(Figs 41-61)

\section{ZooBank taxon LSID:}

B6B3FDB5-90DF-4C1B-AB58-C744B9F3AD9D

Diagnosis. Body length $9.15 \mathrm{~mm}$; pronotum entirely yellow; hemelytron dark brown; anterior lobe of pronotum about 1.10 times longer than posterior lobe, pronotal transverse sulcus obsolete; scutellum with Y-shaped ridges thick, apex of scutellum rounded; fore tibia with fossula spongiosa occupying about $1 / 3$ of tibial length; venter of abdomen only slightly carinate in middle, with a small fusiform extragenital process; left paramere sickle-shaped, right paramere subtriangular; apex of median pygophore process sharp in lateral view; basal portion of dorsal phal- lothecal sclerite slightly upturned; basal margin of right lateral phallothecal sclerite serrate.

Description. Male macropterous (Figs 41-43), female unknown. Coloration. Yellow. First antennal segment yellow, second and third segments brown, fourth segment unknown; head yellow with irregular blackish mark around ocelli (Fig. 44); hemelytron dark brown with forked whitish stripe along outer side of $\mathrm{M}$ and inner side of $\mathrm{R}$ on membrane (Fig. 49); abdomen yellow with some diffuse brown markings laterally (Figs 43, 50).

Structure. Small sized. Head length 1.16 times as long as width; width of interocellar space about twice width of ocellus (Fig. 44); second antennal segment about twice as long as first segment. Pronotum with apex of collar process prominent; anterior lobe of pronotum about 1.10 times longer than posterior lobe; posterior lobe of pronotum about 1.80 times wider than anterior lobe; pronotal transverse sulcus obsolete (Fig. 44). Scutellum with Y-shaped ridges thick, apex of scutellum rounded (Fig. 44). Stridulitrum long with total-striate type of sculpture (Fig. 46). Fore tibia with fossula spongiosa occupying about $1 / 3$ of tibial length (Fig. 47). Venter of abdomen slightly carinate in middle, left side of seventh abdominal sternite with a small fusiform extragenital process (Fig. 50).

Male genitalia: Median pygophore process slender, apex sharp, base with a small spine in lateral view (Fig. 54); left paramere sickle-shaped (Fig. 55), right paramere subtriangular (Fig. 56); basal portion of dorsal phallothecal sclerite slightly upturned (Fig. 59); left lateral phallothecal sclerite moderately sclerotized (Fig. 59); right lateral phallothecal sclerite moderately sclerotized, basal margin serrate (Fig. $60)$.

Measurements [in mm, $\hat{o}(\mathrm{n}=1)$ ]. Body length 9.15; maximum width of abdomen 2.76 ; head length 1.65 ; length of anteocular part 0.69 ; length of postocular part 0.30 ; head width 1.42 ; eye width in dorsal view 0.47 ; width of interocular space 0.50 ; width of interocellar space 0.30 ; lengths of rostral segments I : II : III $=0.69: 0.93: 0.44$; lengths of antennal segments I: II $:$ III $:$ IV $=0.98: 2.02: 1.66:$ ?; length of anterior pronotal lobe 1.26 ; length of posterior pronotal lobe 1.15; width of anterior pronotal lobe 1.50; width of posterior pronotal lobe 2.71 ; scutellum length 1.00; maximum width of scutellum 1.33; hemelytron length 7.14.

Type material. Namibia: Holotype 0 : red-margined "Holotype" disc // "S.W. AFRICA, Otjiw. Dist. 50 km ESE Otjiwarongo Okosongomingo Farm No. $14920^{\circ} 39^{\prime}$ S - 17 $7^{\circ} 05^{\prime}$ E 14 Nov. 1972, C.L. Hogue" // "LACM ENT 196243" (LACM).

Type locality. Namibia, Otjiwarongo District, Okosongomingo Farm No. $149,20^{\circ} 39^{\prime} \mathrm{S}, 17^{\circ} 05^{\prime} \mathrm{E}$.

Etymology. The specific epithet is derived from Greek xan-

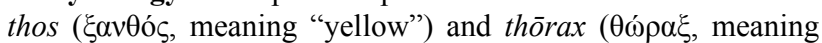
"breastplate"), referring to the entirely yellow pronotum of this new species.

\section{Distribution. Namibia.}

Remarks. This new species is also distributed in Namibia like $N$. bicolor sp. n., and is more similar to $N$. nyassae at first sight. It can be distinguished from the latter species by following characters: body length less than $10 \mathrm{~mm}$ (vs. body length over $10 \mathrm{~mm}$ in $N$. nyassae); antenna with the first segment yellow, the second and the third brown (vs. 
the antenna unicolored in N. nyassae); pronotum entirely yellow (vs. the anterior lobe of the pronotum dark yellow with the posterior lobe brown in $N$. nyassae) and the left side of the seventh abdominal sternite with a small fusiform extragenital process (vs. the venter of the abdomen without an extragenital process in $N$. nyassae). The male genitalia of this new species differ from the male genitalia of $N$. nyassae in having the left paramere sickle-shaped (vs. the left paramere subtriangular in N. nyassae) and the basal portion of the dorsal phallothecal sclerite slightly upturned (vs. the basal portion of the dorsal phallothecal sclerite distinctly upturned in N. nyassae).

\section{DISCUSSION}

\section{Synonymy}

Swanson (2019) established his new genus Sphodrembas with detailed description and illustrations of its type species, S. fumipennis. He recorded the generic diagnosis of Sphodrembas as "Easily separated from all other peiratine genera by the unicarinate metapleuron, apically rounded scutellum, and widely separated metacoxae. The taxon also is distinctive in the thickened pedicel and the testaceous coloration." We examined the holotype of $N$. nyassae deposited in NHMUK and found that this holotype looks similar to the holotype of $S$. fumipennis and the shape of the parameres and median pygophore process, figured in the original description, also match those of $S$. fumipennis.

Swanson (2019) noted that in his new genus Sphodrembas, the unicarinate metapleuron is a condition unknown to him in any other peiratine genus, but also, he had not been able to assess this condition in many of the less speciose genera. Probably Swanson did not examine the holotype of $N$. nyassae, and the special character of the metapleural sulcus, not mentioned by Miller (1952) when he established Neopirates, was probably therefore overlooked. Another unique character that separates Neopirates from other peiratine genera is the indistinct transverse sulcus of the pronotum, recorded by Miller (1952) as "transverse sulcus not entire". Swanson did not include this character in the diagnosis of Sphodrembas but it can be noticed from his close-up view of the pronotum of S. fumipennis.

Swanson (2019) also provided a key to the genera of Peiratinae of the Old World, the characters listed in the key to distinguish Neopirates from some other genera (including Sphodrembas) are "Transverse sulcus of pronotum incomplete medially; scutellum regularly triangular, not produced apically; venation of hemelytral membrane with inner cell narrow, of similar width throughout length (reduviine type); known from Malawi”. Most of these characters are also shared with Sphodrembas and the recorded distribution of $S$. fumipennis (Tanzania and Kenya) and the type locality of $N$. nyassae (Malawi) are not far from each other.

As discussed above, we concluded that $S$. fumipennis should be regarded as a junior synonym of $N$. nyassae and therefore the genus Sphodrembas becomes a junior synonym of Neopirates.

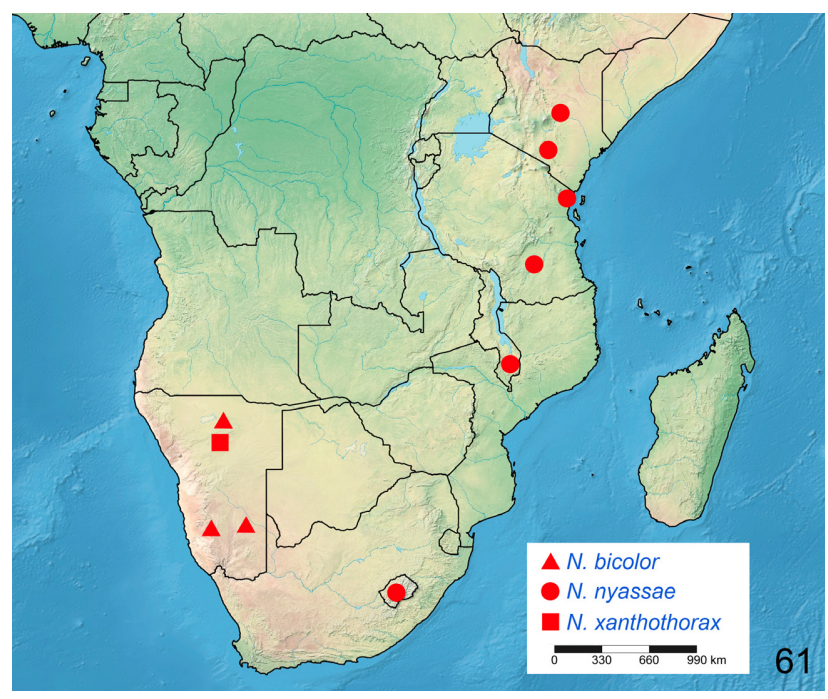

Fig. 61. Known distribution of Neopirates species.

\section{Diagnostic characters and relationships of Neopirates}

The revised diagnosis of Neopirates is given above based on the three included species. This set of characters separates this genus from all other genera of Peiratinae, especially the obsolete or slight pronotal transverse sulcus and the unicarinate metapleural sulcus. Typically, in other peiratinae genera, the metapleural sulcus is created by two closely situated ridges and the pronotal transverse sulcus is distinct or indistinct only in the middle portion.

In the Afrotropical Region, Neopirates is most similar to Peirates, Phalantus and Rapites Villiers, 1948, with a similar body shape and coloration. Besides the two unique characters mentioned above, Neopirates can also be distinguished from Peirates by the anterior lobe of the pronotum subquadrate and the hind coxae separated from each other by the width of one coxa in Neopirates (vs. the anterior lobe of the pronotum rounded and the hind coxae separated from each other less than the width of one coxa in Peirates), and from Phalantus by the fore femur slightly thickened with the ventral surface unarmed and the fore tibia clavate with the fossula spongiosa occupying $1 / 3$ or $1 / 4$ of the tibial length in Neopirates (vs. the fore femur strongly compressed with denticles on the ventral surface and the fore tibia curved with the fossula spongiosa occupying only the apex of the tibia in Phalantus). Rapites differs from Neopirates in the smaller body size, deeper median depression on the anterior lobe of the pronotum and the fossula spongiosa reduced to a brush of hairs.

\section{Distribution and habitat}

Neopirates is distributed in Eastern and Southern Africa (Fig. 61). Neopirates nyassae occurs along the eastern side of the Great Rift Valley and east of the South African plateau in Lesotho. Neopirates bicolor sp. n. and N. xanthothorax sp. n. are both distributed in Namibia's central plateau. The habitats of this genus are mainly savanna regions where the natural vegetation consists of tall grass and short 
deciduous trees. Peiratinae species are primarily grounddwelling and nocturnal (Weirauch et al., 2014). It can be speculated that Neopirates species usually hide in some cryptic microhabitats such as in dead wood or in cracks of rocks in the day time to avoid the high temperature and become active at night.

ACKNOWLEDGEMENTS. We are grateful to W. Xie for the opportunity to study the specimen of $N$. xanthothorax $\mathrm{sp}$. n. from LACM. We appreciate the help given by D. Pluot-Sigwalt and E. Guilbert (Muséum National d'Histoire Naturelle, Paris, France) with the examination of African peiratine specimens deposited in MNHN during a visit by the first author. We also thank V.A. Lemaitre (NHMUK) for checking the manuscript. This research was supported by a grant from the National Natural Science Foundation of China (No. 31730086).

\section{REFERENCES}

CAI W. \& TAYloR S.J. 2006: Lentireduvius, a new genus of Peiratinae from Brazil, with a key to the New World genera (Hemiptera: Reduviidae). - Zootaxa 1360: 51-60.

CHŁond D. 2007: Classification of the true bugs of the subfamily Peiratinae (Heteroptera: Reduviidae). In: Proceedings of the 8th Conference of the Polish Taxonomical Society, Wiechlice, May 18-20, 2007. — Genus (Suppl. 14): 67-69.

ChŁond D. 2018: A taxonomic revision of the genus Sirthenea (Hemiptera: Heteroptera: Reduviidae) of the Old World. Zootaxa 4520: 1-85.

CosCARón M.C. 1995: Redescription of the monotypical genus Parapirates Villiers, 1959 (Heteroptera, Reduviidae, Peiratinae). - Rev. Bras. Entomol. 39: 947-951.

Coscarón M.C. 1997: Revision of the genus Peirates Serville, with a cladistic and biogeographic analysis (Heteroptera: Reduviidae, Peiratinae). - Entomol. Scand. 28: 39-73.

CoscARón M.C. 1999: Redescription of Rapites Villiers 1948 (Heteroptera: Reduviidae: Peiratinae). - Proc. Entomol. Soc. Wash. 101: 619-623.

Coscarón M.C. 2002: Systematic analysis of Calistocoris Reuter, 1881, Ceratopirates Schouteden, 1933, and Pachysandalus
Jeannel, 1916 (Heteroptera: Reduviidae: Peiratinae). — Ann. Mus. Roy. Afr. Centr. (Ser. 8, Sci. Zool.) 290: 27-37.

Coscarón M.C. \& Morrone J.J. 1995: Systematics, cladistics, and biogeography of the Peirates collarti and P. lepturoides species groups (Heteroptera: Reduviidae, Peiratinae). — Entomol. Scand. 26: 191-228.

GHAURI M.S.K. 1964: A remarkable phenomenon amongst the males of Piratinae (Reduviidae, Heteroptera). - Ann. Mag. Nat. Hist. 7: 733-737.

Lent H. \& Wygodzinsky P. 1979: Revision of the Triatominae (Hemiptera, Reduviidae) and their significance as vectors of Chagas' disease. - Bull. Am. Mus. Nat. Hist. 163: 125-520.

MaldonAdO-CAPRILES J. 1990: Systematic Catalogue of the Reduviidae of the World (Insecta: Heteroptera). A special edition of Caribbean Journal of Science, University of Puerto Rico, Mayagüez, $\mathrm{x}+694 \mathrm{pp}$.

Melo M.C. 2012: On the taxonomic placement of the genus Sinnamarynus (Hemiptera: Heteroptera: Reduviidae), and a new record of S. rasahusoides from Peru. — Check List 8: 540-541.

Miller N.C.E. 1952: New Reduviidae in the collection of the British Museum (Natural History Museum). VIII. - Ann. Mag. Nat. Hist. 12: 539-552.

Shorthouse D.P. 2010: SimpleMappr, an Online Tool to Produce Publication-quality Point Maps. URL: https://www.simplemappr.net. (last accessed 22 Oct. 2019).

SwANSON D.R. 2019: Doomed to a vile lot: new taxa, notes, and an updated generic key for the Old World corsairs (Heteroptera: Reduviidae: Peiratinae). - Zootaxa 4700: 196-228.

Weirauch C., Bérenger J.M., Berniker L., Forero D., Forthman M., Frankenberg S., Freedman A., Gordon E., Hoey-ChamBerlain R., Hwang W.S. et al. 2014: An illustrated identification key to assassin bug subfamilies and tribes (Hemiptera: Reduviidae). - Can. J. Arthr. Identif. 26: 1-115.

Zhang G. \& Weirauch C. 2011: Matching dimorphic sexes and immature stages with adults: resolving the systematics of the Bekilya group of Malagasy assassin bugs (Hemiptera: Reduviidae: Peiratinae). - Syst. Entomol. 36: 115-138.

Received June 8, 2020; revised and accepted August 7, 2020 Published online August 28, 2020 